\section{Section 1 Oral presentations}

\section{DIGITAL SEX AND THE CITY: PREVALENT USE OF DATING APPS AMONGST HETEROSEXUAL ATTENDEES OF GENITO-URINARY MEDICINE (GUM) CLINICS}

Malika Mohabeer Hart*, Jey Zdravkov, Komal Plaha, Farhad Cooper, Katie Allen, Lisa Fuller, Rachael Jones, Sara Day. Chelsea and Westminster Healthcare NHS Foundation Trust, London, UK

\subsection{6/sextrans-2016-052718.1}

Background/introduction Studies show that use of dating apps amongst men who have sex with men (MSM) is associated with an increased risk of sexually transmitted infections (STIs), including HIV. There is a paucity of research regarding the use of similar apps amongst the heterosexual population.

Aim(s)/objectives To quantify heterosexual use of dating apps and explore the sexual practices of app users.

Methods Anonymised questionnaires were offered to heterosexual attendees of two GUM clinics, throughout August 2015. Respondents self-completed information relating to purpose and frequency of app use, number of sexual partners, recreational drug use (RDU), condomless sex and STI diagnoses.

Results Questionnaires were returned by 539 attendees: 70\% (377) women, 30\% (162) men. Median age was 21-30 years.

Discussion A quarter of heterosexual GUM attendees frequent apps to find partners. This study identified high rates of STIs, condomless sex and RDU amongst app users, with rates mirroring those seen amongst MSM. Sexual health promotion and/or STI testing packages would be welcomed by most app users. conclusion A quarter of heterosexual GUM attendees frequent apps to find partners. This study identified high rates of STIs, condomless sex and RDU amongst app users, with rates mirroring those seen amongst MSM. Sexual health promotion and/or STI testing packages would be welcomed by most app users.

\begin{tabular}{llll} 
Abstract 0001 Table 1 & Use of mobile phone apps & \\
\hline & Total & Men & Women \\
\hline Ever used dating app & $132(24 \%)$ & $45 / 132(34 \%)$ & $87 / 132(66 \%)$ \\
Frequency of app use & & & \\
Monthly & $34 / 132(26 \%)$ & $14 / 45(31 \%)$ & $20 / 87(23 \%)$ \\
Every few months & $16 / 132(12 \%)$ & $7 / 45(16 \%)$ & $9 / 87(10 \%)$ \\
Reason for app use & & & \\
Seeking long term relationship & $85(64 \%)$ & $11(24 \%)$ & $74(85 \%)$ \\
$\begin{array}{l}\text { Seeking casual sex } \\
\text { Sex with app partner }\end{array}$ & $13(10 \%)$ & $9(20 \%)$ & $4(5 \%)$ \\
$\begin{array}{l}\text { Unprotected } \\
\text { Protected }\end{array}$ & $52(39 \%)$ & $25(56 \%)$ & $27(31 \%)$ \\
RDU with app partner & $59(45 \%)$ & $13(29 \%)$ & $46(53 \%)$ \\
$\begin{array}{l}\text { Diagnosed with STI after } \\
\text { meeting app partner }\end{array}$ & $6(5 \%)$ & $12(26 \%)$ & $1(1 \%)$ \\
$\begin{array}{l}\text { Would request STI testing } \\
\text { kit via app }\end{array}$ & $62 \%$ & $2(4 \%)$ & $4(5 \%)$ \\
$\begin{array}{l}\text { Would value sexual health } \\
\text { information via app }\end{array}$ & $57 \%$ & & \\
\hline
\end{tabular}

\section{RATES OF ASYMPTOMATIC LYMPHOGRANULOMA VENEREUM (LGV) IN MEN WHO HAVE SEX WITH MEN (MSM)}

Tristan Griffiths*, Nneka Nwokolo. Chelsea and Westminster NHS Foundation Trust, London, UK

\subsection{6/sextrans-2016-052718.2}

Background/introduction The 2015 BASHH Chlamydia guidelines recommend LGV testing in asymptomatic HIV positive, but not HIV negative, MSM with rectal chlamydia. Despite evidence for serosorting among MSM having condomless sex, up to $16 \%$ are unaware of, or have different HIV status to their sex partners. HIV positive MSM may therefore transmit LGV to serodiscordent partners, resulting in higher than expected infection rates in HIV negative MSM.

Aim(s)/objectives To compare rates of asymptomatic and symptomatic LGV in HIV positive and negative MSM attending a sexual health service.

Methods Case notes of individuals with confirmed LGV from 8/ $6 / 2015-31 / 12 / 2015$ were reviewed and data on demographics, symptoms, HIV status and presence of other STIs collected.

Results We identified 105 cases of LGV (79\% White; median age 35.3 years). 48 (46\%) were HIV negative. 73\% of HIV negative and $56 \%$ of HIV positive individuals were asymptomatic. 50 patients $(47.7 \%)$ had one or more other STIs at time of initial LGV diagnosis; 62\% were HIV positive. At time of censor, $95 \%$ of individuals attending for test of cure had a negative result.

Discussion/conclusion Asymptomatic LGV was identified in 73\% of HIV negative individuals which is likely to have been missed had they not been tested at initial chlamydia diagnosis. STIs facilitate onward transmission of HIV and our findings highlight the importance of continuing to recommend regular screening in all MSM regardless of HIV status to identify infections and offer timely treatment. We recommend LGV testing be extended to asymptomatic HIV negative MSM with rectal chlamydia.

\section{SALIVA USE AS A LUBRICANT FOR ANAL SEX IS A RISK FACTOR FOR RECTAL GONORRHOEA AMONG MEN WHO HAVE SEX WITH MEN, A NEW PUBLIC HEALTH MESSAGE: A CROSS-SECTIONAL SURVEY}

\footnotetext{
1,2Eric PF Chow, ${ }^{2}$ Vincent I Cornelisse, 1,2Tim RH Read, ${ }^{1,3}$ David M Lee*, ${ }^{2}$ Sandra Walker, ${ }^{3}$ Jane S Hocking, ${ }^{1,2}$ Marcus Y Chen, ${ }^{1,2}$ Catriona S Bradshaw, ${ }^{1,2}$ Christopher K Fairley. ${ }^{1}$ Melbourne Sexual Health Centre, Alfred Hospital, Melbourne, Australia; ${ }^{2}$ Monash University, Central Clinical School, Faculty of Medicine, Nursing and Health Sciences, Melbourne, Australia; ${ }^{3}$ University of Melbourne, Melbourne School of Population and Global Health, Melbourne, Australia
}

\subsection{6/sextrans-2016-052718.3}

Background/introduction Apart from penile-anal intercourse, other anal sexual practices (oral-anal contact or rimming, fingering and saliva use as a lubricant for anal sex) are common among men who have sex with men (MSM).

$\operatorname{Aim}(\mathbf{s}) /$ objectives The aim of this study is to evaluate whether these anal sexual practices are risk factors for rectal gonorrhoea in MSM.

Methods A cross-sectional survey was conducted among MSM attending a large urban sexual health centre between July 2014 and June 2015. Rectal gonorrhoea cases were identified by culture. 
Results Among 1312 MSM, 4.3\% ( $\mathrm{n}=56$ ) had rectal gonorrhoea. Anal sexual practices, other than anal-penile sex, were common among MSM: receptive oro-anal (rimming) (70.5\%), receptive fingering or penile-perianal contact i.e dipping $(84.3 \%)$ and using partner's saliva as a lubricant for anal sex (68.5\%). Saliva as a lubricant (adjusted OR 2.17; 95\% CI 1.00 to 4.71) was significantly associated with rectal gonorrhoea after adjusting for potential confounding factors. Receptive rimming and fingering or penis dipping were not statistically associated with rectal gonorrhoea. The crude population attributable fraction of rectal gonorrhoea associated with use of partner's saliva as a lubricant for anal sex was $48.9 \%$ (7.9\% to $71.7 \%)$.

Discussion/conclusion Saliva use as a lubricant for anal sex is a common sexual practice in MSM, and may play an important role in gonorrhoea transmission. Almost half of rectal gonorrhoea cases may be eliminated if a message of prevention is included in not using partner's saliva for anal sex.

\section{O004 INHIBITORY EFFECT OF AN ANTISEPTIC MOUTHWASH AGAINST NEISSERIA GONORRHOEAE IN THE PHARYNX (GONE) AMONG MEN WHO HAVE SEX WITH MEN: A RANDOMISED CONTROL TRIAL}

\begin{abstract}
${ }^{1,2}$ Eric Chow, ${ }^{3}$ Benjamin Howden, ${ }^{3}$ Kerrie Stevens, ${ }^{1}$ Sandra Walker*, ${ }^{1}$ David Lee, ${ }^{1}$ Anthony Snow, ${ }^{1}$ Stuart Cook, ${ }^{1}$ Glenda Fehler, ${ }^{1,2}$ Catriona Bradshaw, 1,2 Marcus Chen, ${ }^{1,2}$ Christopher Fairley. 'Melbourne Sexual Health Centre, Alfred Health, Melbourne, VIC, Australia; ${ }^{2}$ Central Clinical School, Faculty of Medicine, Nursing and Health Sciences, Melbourne, VIC, Australia; ${ }^{3}$ Microbiological Diagnostic Unit Public Health Laboratory, Department of Microbiology and Immunology, The University of Melbourne, at the Peter Doherty Institute for Infection and Immunity, Melbourne, VIC, Australia
\end{abstract}

\subsection{6/sextrans-2016-052718.4}

Background/introduction Gonorrhoea prevalence is increasing among men who have sex with men (MSM) worldwide. Studies suggest pharyngeal infection may be central to transmission and is the site of acquisition of resistant genes. With condom use falling, other interventions to reduce the transmission of gonorrhoea are urgently required.

Aim(s)/objectives To determine whether Listerine, a commercial mouthwash product, has an inhibitory effect against $N$. gonorrhoeae.

Methods MSM who tested positive for pharyngeal gonorrhoea by nucleic acid amplification test between May-2015 and February-2016 and returned for treatment within 14 days, were enrolled in the study. They were randomised to gargle either Listerine or saline for 60 seconds. Pharyngeal swabs were taken before and after gargling, and tested by culture. Only men who tested positive by culture before gargling were included in the analysis. The proportions of men who tested positive for pharyngeal gonorrhoea after gargling in both groups were calculated. Results Of the 197 MSM who enrolled, only 58 MSM (33 in Listerine arm and 25 in saline arm) tested positive by culture on the day of recruitment. 17 (52\%) MSM in the Listerine arm remained culture positive versus 21 (84\%) in the saline arm after gargling the solution $(p=0.013)$. The odds of being culture positive were 4.4 (95\% CI: 1.4-17.7) times higher among men who gargled saline compared to those gargled Listerine.

Discussion/conclusion This data suggest Listerine could reduce the viable numbers of $N$. gonorrhoeae on pharyngeal surface which may prevent transmission. Further trials to look at efficacy over time are warranted.

\section{SELF-TAKEN EXTRA-GENITAL SAMPLES COMPARED WITH CLINICIAN-TAKEN EXTRA-GENITAL SAMPLES FOR THE DIAGNOSIS OF GONORRHOEA AND CHLAMYDIA IN WOMEN AND MSM}

${ }^{1}$ Janet Wilson*, ${ }^{1}$ Harriet Wallace, ${ }^{1}$ Michelle Loftus-Keeling, ${ }^{2}$ Helen Ward, ${ }^{3}$ Claire Hulme, ${ }^{4}$ Mark Wilcox. 'Leeds Sexual Health, Leeds Teaching Hospitals NHS Trust, Leeds, UK; ${ }^{2}$ Department of Infectious Disease Epidemiology, Imperial College, London, UK; ${ }^{3}$ Academic Unit of Health Economics, University of Leeds, Leeds, UK; ${ }^{4}$ Department of Clinical Microbiology, Leeds Teaching Hospitals NHS Trust, Leeds, UK

\subsection{6/sextrans-2016-052718.5}

Background Extra-genital tests for gonorrhoea and chlamydia are important in MSM and are increasingly important in women as vulvovaginal swabs (VVS) alone can miss infections. Self-sampling is frequently used but there has been no robust RCT against clinician-taken samples in MSM or women to assess its efficacy.

Aim To compare self-taken extra-genital samples in women and MSM with clinician-taken samples for diagnostic accuracy.

Methods Women and MSM attending a sexual health clinic were invited into a 'swab yourself' trial. Clinician and self-samples were taken from the pharynx and rectum (plus VVS in women and FCU in MSM) for gonorrhoea (NG) and chlamydia (CT) using NAATs. The sampling order was randomised. Patient infected status was defined as at least two positive confirmed samples.

Results 1251 women and MSM were recruited to January 2016. Overall prevalence: NG 5.7\% (rectal 4.3\%, pharyngeal 3.1\%), CT $17.8 \%$ (rectal 16.5\%, pharyngeal $4.0 \%$ ). 9.4\% of female NG cases and $13.8 \%$ of CT cases were VVS negative. $72 \%$ of MSM NG cases and $89.5 \%$ of CT cases were FCU negative.

Sensitivity, specificity, PPV and NPV are shown in the table:

\begin{tabular}{|c|c|c|c|c|}
\hline & $\begin{array}{l}\text { Sensitivity } \\
(95 \% \mathrm{Cl})\end{array}$ & $\begin{array}{l}\text { Specificity } \\
(95 \% \mathrm{Cl})\end{array}$ & $\begin{array}{l}\text { PPV } \\
(95 \% \mathrm{Cl})\end{array}$ & $\begin{array}{l}\text { NPV } \\
(95 \% \mathrm{Cl})\end{array}$ \\
\hline NG rectal clinician & $\begin{array}{l}96.3 \\
(87.3-99.6)\end{array}$ & $\begin{array}{l}100.0 \\
(99,7-100.0)\end{array}$ & $\begin{array}{l}100.0 \\
(93.2-100.0)\end{array}$ & $\begin{array}{l}99.8 \\
(99.4-100.0\end{array}$ \\
\hline NG rectal self & $\begin{array}{l}98.2 \\
(90.1-100.0)\end{array}$ & $\begin{array}{l}99.9 \\
(99.5-100.0)\end{array}$ & $\begin{array}{l}98.2 \\
(90.1-100.0)\end{array}$ & $\begin{array}{l}99.9 \\
(99.5-100.0)\end{array}$ \\
\hline NG pharynx clinician & $\begin{array}{l}95.1 \\
(83.5-99.4)\end{array}$ & $\begin{array}{l}100.0 \\
(99.7-100.0)\end{array}$ & $\begin{array}{l}100.0 \\
(91.0-100.0)\end{array}$ & $\begin{array}{l}99.8 \\
(99.4-100.0)\end{array}$ \\
\hline NG pharnyx self & $\begin{array}{l}97.6 \\
(87.4-99.9)\end{array}$ & $\begin{array}{l}100.0 \\
(99.7-100.0)\end{array}$ & $\begin{array}{l}100.0 \\
(91.4-100.0)\end{array}$ & $\begin{array}{l}99.9 \\
(99.5-100.0)\end{array}$ \\
\hline $\mathrm{CT}$ rectal clinician & $\begin{array}{l}96.6 \\
(93.1-98.6)\end{array}$ & $\begin{array}{l}99.9 \\
(99.5-100.0)\end{array}$ & $\begin{array}{l}99.5 \\
(97.2-100.0)\end{array}$ & $\begin{array}{l}99.3 \\
(98.6-99.7)\end{array}$ \\
\hline CT rectal self & $\begin{array}{l}98.1 \\
(95.1-99.5)\end{array}$ & $\begin{array}{l}99.8 \\
(99.3-100.0)\end{array}$ & $\begin{array}{l}99.0 \\
(96.5-99.9)\end{array}$ & $\begin{array}{l}99.6 \\
(99.0-99.9)\end{array}$ \\
\hline CT pharynx clinician & $\begin{array}{l}92.0 \\
(80.8-97.8)\end{array}$ & $\begin{array}{l}99.9 \\
(99.5-100.0)\end{array}$ & $\begin{array}{l}97.9 \\
(88.7-100.0)\end{array}$ & $\begin{array}{l}99.7 \\
(99.2-99.9)\end{array}$ \\
\hline CT pharynx self & $\begin{array}{l}96.0 \\
(86.3-99.5)\end{array}$ & $\begin{array}{l}99.9 \\
(99.5-100.0)\end{array}$ & $\begin{array}{l}98.0 \\
(89.2-100.0)\end{array}$ & $\begin{array}{l}99.8 \\
(99.4-100.0)\end{array}$ \\
\hline
\end{tabular}

No statistical difference between self and clinician-taken rectal or pharyngeal samples by McNemar test.

Conclusion This on-going work is the first randomised study showing that self-taken extra-genital samples have high sensitivity and specificity and are comparable to clinician-taken samples. High levels of extra-genital infections were found. In women $9 \%$ of NG and 14\% of CT infections would be missed using VVS alone demonstrating the benefit of extragenital sampling. 